\title{
ARTICLE
}

\section{Green human resouce management: a Theoretical review}

Oyun Tuul* and Shao Jian Bing

Business School, University of Liaoning, PR China

Abstract: In the $21^{\text {st }}$ century, environmental issues, such as climate change, global warming, and air pollution have become a hot topic in many developed and developing countries. At the same time, the proper use of natural resources and the conservation of the environment has become one of the vital issues. Environmental issues require special attention from governments, scientists, scholars, business executives, and even individuals.

Therefore, for any business organization, there is a growing need to integrate environmental management into human resource management, which has been coined as the Green Human Resource Management (GHRM). Researchers have found that the implementation of GHRM policies and practices could effectively improve financial and environmental performance of organizations, improve their competitive advantage, as well as improve their reputation and image, while maintaining environmental management practices.

However, it is being maintained that the term "GHRM" is a relatively new concept for academicians, scholars, and professionals. GRHM-related literature is generally found in western countries, however the concept of GHRM is yet to make its mark in Asia. Therefore, the aim of this research is to explore the concept of GHRM and to propose a model of GHRM and its outcome by reviewing the literature.

Keywords: Human Recource Management (HRM); Environment Management (EM); Green Human Resource Management (GHRM);

\section{INTRODUCTION}

Today we are living in an era of industrialization, where millions of organizations are working throughout the world. These organizations produce enormous amounts of wastethat are hazardous for humans, which also pollute the environment adversely [20]. In the past, organizational policies and practices were highly dependent on gaining economic values, but in the present, growing environmental concerns have changed the entire scenario, and the paradigm has shifted to minimizing the carbon footprint and promoting environment sustainability, ensuring ecological equilibrium as well as enhancing societal conditions [10].

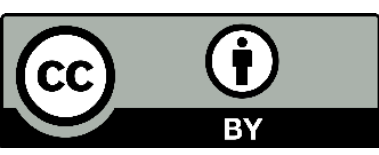

The Author(s). 2020 Open access This article is distributed under the terms of the Creative Commons Attribution 4.0 International License (https://creativecommons.org/licenses/by/4.0/), which permits unrestricted use, distribution, and reproduction in any medium, provided you give appropriate credit to the original author(s) and the source, provide a link to the Creative Commons license, and indicate if changes were made. 
In other words, environmental problems have brought to the fore the need for environment-conscious activities at the individual, organizational, and community levels. These activities are generally implemented on a voluntary basis, but sometimes implemented within the scope of legal obligations [1].

Today, organizations are trying to address environemtal problems, looking for a strategy, which is economically viable as well. For any business organization, HR constitutes an essential function to implement a new strategy. Therefore, in 1996, Wehremeyer first put forward a new method of combining environmental management with human resource management to resolve environment issues. The term "GHRM" is often used to refer to the contribution of HR policies and practices towards environmental issue, which are broadly categorized into two elements, i.e. environmentally-friendly HR practices and the

\section{MATERIALS AND METHODS}

The key research objective is to study the concept of GHRM and to explore the outcomes after adopting the GHRM in the organizations.

This paper employs the methodology to review articles cited in such databases as Google Scholar, ResearchGate, Sage, ScienceDirect, Emerald etc.

\section{Literature review}

Going green: Recently reseachers have cited increased awareness within business organizations about the significance of going green and adopting various environment management techniques. Going green, environmental protection, sustainable life style, protecting our earth and many more have become a natural phenomenon in our everyday life [3].

Researchers such as Rani and Mishra (2015), Deshwal (2015), Opatha and Arulrajah (2014), in their studies have indicated that 'Green' or 'Greening' has at least four meanings.

1. Protection of natural resource. This means to keep the environment in its original form preservation of human capital [10,24,31]. In addition, GHRM consists of all activities aimed at helping an organization carry out its agenda for environmental management that enables it reduce its carbon footprint and earn carbon credits, as well as in areas concerning acquisition of manpower, their induction, performance management, training and development, compensation and reward management [8].

However, such researchers as Renwick., et al (2013), Rayner., et al (2018) have asserted that GHRM research raises new, increasingly salient questions not yet studied in the broader HRM literature. In other words, the term "GHRM" today has become the buzzword within the business realm, however the concept of GHRM is relatively unknown, and the way organizations implement these practices is vague in many developed and developing countries alike.

and protect it from harm, loss, or negative change. The resources need to be preserved; everyone can do their part to protect the natural environment.

2. Preservation of natural environment: Enforcing laws alone is not enough to protect the environment for the future. In nature nothing is wasted because everything has a purpose. There are different ways in which the natural environment can be preserved, such as resource in cycles or in the form of circle.

3. Avoidance of Environmental Pollution: The pollution prevention act of 1990, enacted by the United States congress, requires that pollution of the environment should be reduced in a descending order. Firstly, resource elimination, secondly sound recycling, sound treatment and finally, sound disposal treatment.

4. Greening people, means creating awareness among people in the surrounding. Focus on the "go green" concept. 
Green Human Resource Management: GHRM concept was first introduced by Wehremeyer in 1996, and he attempted to connect the two fields of EM and HRM. Since then, the concept of GHRM gained global popularityy in the 2000 s, and since studies on GHRM has been gaining momentum. However, there is no systematic and valid instrument for measuring the concept [33]. In literature, numerous researchers have given different definitions of GHRM.

GHRM is most regularly used to refer to the concern of people management policies and practices towards the broader corporate environmental agenda [7,10,16,21,22,26]. Moreover, GHRM encompasses all activities aimed at helping an organization carry out its agenda for environment management to reduce its carbon footprint in areas of concern, such as recruitment of human resources, their induction, performance appraisal and management, training and development, remuneration and reward management [35].

GHRM is about a set of HR practices aimed at improving greener performance of individuals and organizations; and it supports organization's EM initiatives [34]. In addition, it contributes to understanding the role of HRM embracing sustainability issues. They include, for instance promoting a green culture, engaging workers in reducing waste, using resources more efficiently and harming the environment as little as possible [25].

GHRM practices and policies should be able to systematically coordinate all individual HRM measures so as to directly influence employee attitude and behavior in a way that helps a business to achieve its competitive strategy [1,22]. Mehtab-un-Nisa.,et al (2016) conducted research on the effects of GHRM practices on sustainability among 354 employees from 13 manufacturing companies in Pakistan and the results prove a significant effect of all GHRM dimensions on sustainability.

Bangal and Tiwari (2015) in their study have noted that GHRM can develop willingness, inspiration and commitment among employees to dedicate their efforts and ideas to the greening of their organization. GHRM efforts result in increased efficiency, sustainable utilization of resources, less wastage, improved job related attitude, improved work/private life, lower costs, improved employee performance and retention, which help an organization to reduce employee carbon footprints by means of GHRM.

Nejati and Ahmad (2015) found that both company's attractiveness and prestige, resulting from GHRM practice, could significantly influence job seekers' intention to pursue their application with a company.

In developed western countries, there are already some leading businesses, such as Google, Coca Cola and Dell, which have started operationalizing the practice of GHRM $[10,12,24,26,30]$. GHRM practices include electronic filing, teleconferencing and virtual interviews, polling rides, job sharing, recycling, telecommuting, online training, and developing more energy efficient office spaces [23, 25, 29].

This research briefly describes five specific HR practices such as green recruitment and selection, green training and development, green performance appraisal, green rewards and compensation, and green employee participation.

Green Recruitment and Selection: Successful recruitment and selection practices are key elements of an organization. The most daunting challenge encountered by HR managers is to hire and sustain highly skilled and professional employees in in the global competitive environment [4]. It is believed that recruiting candidates, who are eco-friendly, can help make a dent in environmental and organizational performance [5].

Green recruitment can be defined as the process of hiring individuals with knowledge, skills, approaches, and behaviors that identify with environmental management systems within an organization [2]. Based on previous studies, Guiyao Tang., et al (2018) have summarized green recruitment and selection in three aspects: candidates' green awareness, green employer branding, and green criteria to attract candidates.

To accomplish the green recruitment process through digital method online application form, online interviews or telephonic interviews are conducive to reducing paper wastage, fuel consumption and interview 
travels. This practice decreases the rate of environmental degradation. In other words, the move to more web-based recruitment activity has permitted recruiters to provide much more information, such as the details of their EM activities, compared with traditional media such as newspaper advertising or brochures [26].

Recruitment practices can help improve environmental sustainability by ensuring that environmental culture and values are crystal clear to the newly recruited employees [6]. Mwita and Kinemo(2018) investigated the impact of green recruitment and selection on performance. Their research found that green recruitment and selection practices are in place and they contribute to attracting better qualified job candidates. Moreover, the study also found a linear relationship between green recruitment and selection, and performance.

Green Training and Development: Green training and development are seen in the literature as a key to accomplishing the environmental objective. Zoogah (2011) states that green training and development educate employees about the value of EM, train them in working methods that conserve energy, reduce waste and spread environmental awareness within the organization, and provide possibilities to engage employees in environmental problem-solving. Sharma and Gupta (2015) stated that environment management as an element of GHRM, training and development should focus on the development of employee's skill, knowledge, attitudes and behaviour about environment conservation and environment initiatives.

Moreover, one more integral element of GHRM implementation is environmental protection, renewable energy, waste reduction and energy saving training. Such training allows employees to gain ecological knowledge and raise environmental awareness. Research indicates that this is the most important element of the process of HRM and facilitates the attainment of environmental objectives [23].

Menon (2016) conducted reseach among 237 managers and found that most of the organizations encourage employees and create awareness among the employee to develop the organization as a green entity.
Nejati and Ahmad (2015) found training to be the most prominent element, for it could positively influence job seekers' perception toward attractiveness and prestige of company.

Good examples of company environmental training in Britain include those at Carson Office Furniture Systems, ReadyMixed Concrete, Rolls-Royce, Albion Group, and Bristol-Myers Squibb, who provide induction training for new staff, awareness training for more experienced employees, and training on specific green topics for staff specifically associated with environmental operations and co-ordination [35].

Green Performancee and Appraisal: Performance management is a range of activities undertaken to ensure proper management of staff's performance. Green performance management is about designing such a performance management system where green performance of employees can be accomplished using such means as recording and reporting of environmental incidents, communication of environmental concerns and policy and so on and so forth [27]. Reseachers have found that the idea behind green performance management is to develop EM related objectives, responsibilities, EM behavior, and green rating as part of employee's performance evaluation. Regular feedback from supervisor to employees regarding their EP related achievement is also very useful in improving employee's knowledge, skills, and abilities related to the EM.

Green Rewards and Compensation: Rewards and compensation are the major HRM processes through which employees are rewarded for their performance. In the context of GHRM, rewards and compensation can be assumed as potential tools for supporting environmental activities in organizations [2]. In their strategic approach to reward and management, modern organizations are developing reward systems to encourage ecofriendly initiatives embarked upon by their employees [2]. Therefore, organizations need reward systems that enable desirable green behaviour by means of incentives as well as disincentives. Nejati and Ahmad (2015) found that reward has a positive impact on a company's attractiveness and prestige. 
There are many types of reward practices that organizations may use for green skills acquisition. Rewards can be in the form of financial based EM rewards (e.g. premium, cash, bonuses), nonfinancial based EM rewards (e.g. leave, gifts, sabbatical), recognition-based EM rewards (e.g. external roles, daily praise, dinners), and positive rewards in EM (e.g. feedback) [14, 19,27].

Green Employee Participation: EM can be achieved through proper employee involvement and employee participation [14]. The use of employee participation in EM has been noted to help prevent pollution at workplaces [36]. Researchers have found that employees' green involvement is crucial in improving the performance of EM systems, such as reducing waste and pollution in workplaces and making full use of resources. Renwick et al. (2013) identified five aspects for measuring green involvement: clear green vision, a green learning climate, various communication channels that offer green practices, and green involvement.

Benefits of GHRM: Researchers such as Butoliya (2015), Deshwa (2015), Sharanya, S and Radhika, R (2016), Sharma, K (2016), Sindhwani and Saxena (2015) have outlined in their studies the following benefits of applying GHRM in organizations:

- It develops sustainable organization.

- It facilitates the implementation all the stages of environmental management system

- It provides competitive advantage to the company in industry as well as the market.

- It helps in the efficient utilization of resources and manages risks more effectively.

\section{RESULTS AND DISCUSSION}

Based on the analysis of the literature, a conceptual model framework of GHRM and its outcomes have been developed (see Figure 1).

This research has analyzed the literature on GHRM and presented a model in GHRM. In recent years, because of growing need for the preservation or conservation of natural resources and prevention of environmental pollution, it is becoming increasingly
- It reduces energy consumption.

- It increases sales.

- It reduces insurance costs.

- It has a direct impact on the profit and return on investment.

- It increases employee morale.

- It helps in employee retention and reduces labour turnover.

- It helps in building company image to attract good human resources.

- It improves brand image of the organization in the market.

- It can also be used as a marketing strategy.

- It improves the quality, both internal and external, of the overall organization.

- It reduces the overall cost of the organization.

Challenges of GHRM: Alongside the above-mentioned advantages and/or benefits, GHRM faces certain challenges, which can be identified as follows:

- It is difficult to alter the behavior of employees in a short span of time.

- Not every employee is equally motivated to participate in the promotion of GHRM practices in the organization.

- Developing the culture of GHRM in the entire organization is a cumbersome and a time-consuming process.

- It requires high initial investment and comparatively slow rate of return.

- Sourcing and recruitment of green employees with quality talents is a challenging task.

- It is difficult to measure the effectiveness of GHR practices in employees' behavior.

importantf for an organization to adopt environmental strategies and programmes. For any organization, the HRM function becomes the potential contributor in bringing about the requisite organizational change. So, there is an emerging need to integrate environmental management and HRM to reduce environmental problems. 


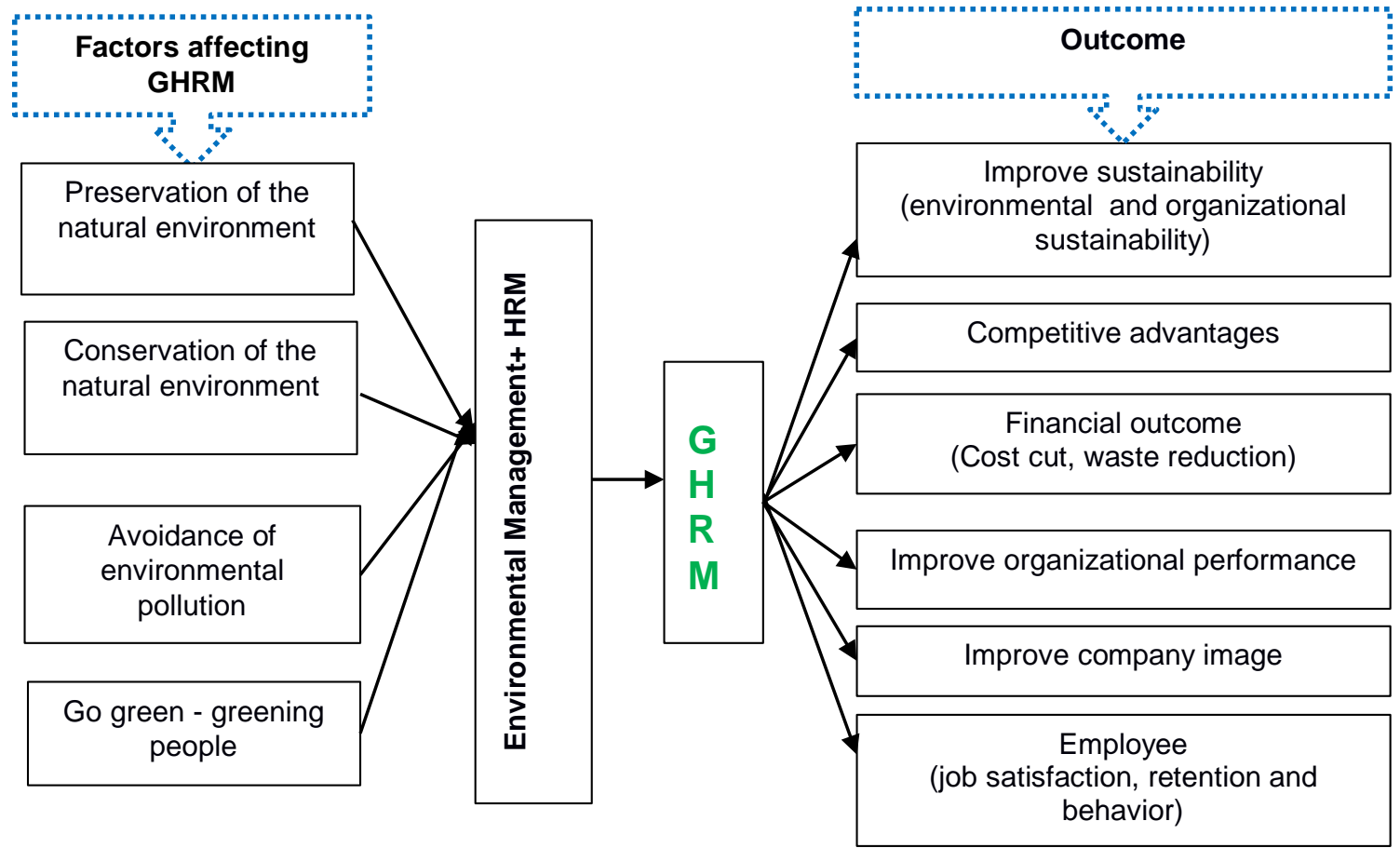

Figure 1. Conceptual model (GHRM and its outcomes)

Practicing GHRM in an organization yields many positive outcomes. First of all, GHRM promotes the sustainable use of resources within an organization and, more generally, promotes the causes of environment sustainability. In other words, GHRM is an effective tool in making a business sustainable. Furthermore, organizations that are sustainable have far better chances of improving their

\section{CONCLUSIONS}

This research reviewed the concept of "GHRM". The concept of GHRM is still a new idea, which is at its infancy stage. However, western organizations have started realizing the importance of these practices and are trying to operationalize them. GHRM practices include electronic filing, teleconferencing and virtual

\section{REFERENCES}

1. Aykan, E (2017) Gaining a competitive advantage through Green Human Resource Management. pp.160-175. doi.org/10.5772/intechopen.69703.

2. Banerjee, S., Dutta, A, B (2017) Green HRM: A Brief Review. Rainbow reputation and image, as well as their financial performance, which in its turn will improve their competitive edge. GHRM also helps makes green employees so that they eliminate wastes and reduce overall costs of the organization. Additionally it influences employee satisfaction, retention and behavior through GHRM.

interviews, pooling rides, job sharing, recycling, telecommuting, online training etc. GHRM practices help an organization improve its competetitve advantage, save money, reduce costs, and build up the organization's image to attract good HR etc.

Multidisciplinary Pre-Reviewed Annual Journal, (3). pp.1-5.

3. Bangwal D., Tiwari, P (2015) Green HRM - A way to greeting the environment. Journal of Business and Management, (17), 2. pp. 45-53. 
4. Bhutto, S.A., Auranzeb (2016) Effects of Green Human Resource Management on firm performance: An empirical study on Pakistani firms. European Journal of Business.

5. Bombiak, E., Marciniuk-Kluska, A (2018) Green Human Resource Management as a Tool for the Sustainable development of enterprises: Polish young company experience.

6. Management, (8), 16. pp. 119-125. www.mdpi.com/journal/sustainability

7. Das, S. C., Singh, R. K (2016) Green HRM, and organizational sustainability: An empirical review. Kegees Journal of Social Science (8) 1,2. pp. 227-236.

8. Deshwal, P (2015) Green HRM: An organizational strategy of greening people. International Journal of Applied Research. (1), 13. pp. 176-181.

9. Hosain, S., Rahman, S (2016) Green Human Resource Management: A theoretical overview. Journal of Business and Management, (18), 6. pp. 54-59.

10. Javed, F., Cheema, S (2017) An empirical investigation on the impacts of the adoption of Green HRM in the agricultural industry. Journal of Internet Banking and Commerce. (22),58. pp. 1-14.

11. Kaur, S., Gupta, P (2016) Green Human Resource Management and Indian Industries. International Journal of Multidisciplinary Allied Research Review and Practices, (3),5. pp. 573-583.

12. Kotkar, S. N., Bhadani, R (2016) Go green and gain competitive advantage. International Journal in Management and Social Science, (4), 9. pp.140-144.

13. Likhitkar, P., Verma, P (2015) Impact of green HRM practices on organization sustainability and employee retention. International Journal for Innovative Research in Multidisciplinary Field, (3),5. pp. 152-157.

14. Mandip, G (2012) Green HRM. People management commitment to environmental sustainability. Research journal of recent sciences, (1). pp. 244-252.

15. Mehta, K., Chugan, P. K (2015) Green HRM in pursuit of environmentally sustainable business. Universal Journal of
Industrial and Business Management, (3),3. pp. 74-81.

16. Mehtab-un-Nisa., Mahmood, A., Sandhu, A. S., Kanwal, S., Iqbal, J (2016) The Effect of Green HRM practices on sustainability: Evidence from manufacturing companies in Pakistan. Pakistan Journal of Social Sciences (PJSS) (36) 1. pp. 177-188.

17. Menon, B.N (2016) A study of Green HR practices and strategic implementation in the Kolhapur based industries. Indian Streams Research Journal, (6),2. pp. 1-8. https://www.researchgate.net/publication/ 308109619

18. Mwita, K. M., Kinema, S. M (2018) The role of green recruitment and selection on performance of processing industries in Tanzania: A case of Tanzania Tobacco Limited (TTPL). International Journal of Human Resource Studies, 8 (3). pp. 35-46.

19. Nejati, M., Ahmad, N.H (2015) Job seekers' perception of Green HRM. Conference on Green Human Resource Management, Malaysia. pp. 92-101.

20. Opatha, H. H. D. N. P., Arulrajah, A. A (2014) Green Human Resource Management: Simplified general reflections. International Business Research, (7),8. pp. 101-112.

21. Paille', P., Chen, Y., Boiral, O., Jin, J (2013) The Impact of Human Resource Management on Environmental Performance: An Employee-level study. Springer Science Business Media Dordrecht. pp. 1-16.

22. Parveen, S. J M., Phil, M (2018) Green Human Resource Management (GHRM). International Journal of Research and Analytical Reviews. (5), 3. pp. 251-254.

23. Putra, A.W.G (2011) "Green” HRM: An evaluation and the future agenda. Business and Entrepreneurial Review, (10),2. pp.131-138.

24. Rajiani, I (2015) Conceptualizing Strategic Green Human Resources Management to Boost Environmental Performance. https://www.researchgate.net/publication/ 281091966

25. Rani, S., Mishra, K (2014) Green HRM: Practices and Strategic implementation in 
the organizations. International Journal on Recent and Innovation Trends in Computing and Communication, (2),11. pp. 3633-3639.

26. Rayner, J., Morgan, D (2018) An empirical study of 'Green' workplace behaviors: Ability, motivation, and opportunity. Asia Pacific Journal of Human Resources, (56). pp. 56-78.

27. Reddy, Y. V. P (2017) Green HRM Initiatives: Practices and strategic implementation within the organization. Abhinav National Monthly Refereed Journal of Research in Commerce \& Management, India, (6),11. pp. 62-29.

28. Renwick, D. W. A., Redman, T., Maguire, $S$ (2012) Green Human Resource Management: A review and Research agenda. International Journal of Management Reviews, (1),15. pp. 1-14.

29. Rimi, N.N (2016) Green HRM for green services: A proposed best practices Green HRM model for green banking performance in Bangladesh. European Journal of Business and Management, (8), 8. pp. 60-69.

30. Sharanya, S., Radhika, R (2016) A study on Green Human Resource Practice in IT sector with special reference to Technopark. Journal of Chemical and Pharmaceutical Sciences, (9), 1. pp. 396401.

31. Sharma, K (2016) Conceptualization of Green HRM and Green HRM Practices: Commitment to Environment Sustainability. International Journal of Advanced Scientific Research and Management, (1),8. pp. 74-81.
32. Sharma, R., Gupta, N (2015) Green HRM: An innovative approach to environmental sustainability. Twelfth AIMS International Conference on Management. pp. 825-830

33. Sindhwani, B, K., Saxena, A, K (2015) Role of HR Professionals for Green Human Resource Management and The Impact of Green Awareness at the Workplace. IJEMR, (5), 11. pp. 1-16.

34. Tang, G., Chen, Y., Jiang, Y., Paile, P., Jia, $J$ (2018) Green human resource management practice: Scale development and validity. Asia Pacific Journal of Human Resource, (56). pp. 31-55.

35. Tahir, M., Rahim, Z., Khan, R. A (2017) GREEN HRM-introduction, predictors, outcomes, and future prospects in Pakistan. Iqra Journal of Business \& Management, (1)1. pp. 24-32.

36. Uddin, M. M., Islam, M. R (2015) Green HRM: Goal Attainment through Environmental Sustainability. The Journal of Nepalese Business Studies, (9),1. pp. 1319.

37. Zaid, A. A., Bon, A. T., Jaaron, A. A. M (2018) Green Human Resource Management bundle practices and manufacturing organizations for performance optimization: A conceptual model. International Journal of Engineering \& Technology, (3),7. pp.8791.

38. Zoogah, D. B (2011) The dynamics of green HRM behaviors: A cognitive-social information processing approach. German Journal of Research in Human Resource Management, 25, (2). pp. 117-139. 